\title{
SAFE avdekker \\ funksjonssvikt hos hjemmeboende eldre
}

Sykepleiere kan lettere oppdage endringer i helsen til hjemmeboende pasienter når de bruker SAFEverktøyet med jevne mellomrom.

\section{Edith Roth Gjevjon}

Instituttleder

Lovisenberg diakonale høgskole

\section{Silje Christin Wang Linnerud}

Høgskolelektor

Lovisenberg diakonale høgskole

\section{Ellen Andersen}

\section{Seksjonssjef}

Senter for fagutvikling og forskning / Utviklingssenter for sykehjem og hjemmetjenester, Oslo kommune

\section{Mette Sophie Klev}

Fagsykepleier og intensivsykepleier

Senter for fagutvikling og forskning / Utviklingssenter for sykehjem og hjemmetjenester, Oslo kommune

\section{Steinar Johansen}

Høyskolelektor

Lovisenberg diakonale høgskole

\section{Gunilla Borglin}

\section{Dosent}

Malmö universitet, Institutionen för vårdvetenskap 


\section{Hovedbudskap}

SAFE er et verktøy som har til hensikt å avdekke tidlige tegn på subakutt og akutt funksjonssvikt hos hjemmeboende eldre. SAFE er erfarings- og forskningsbasert, og utviklet og testet i og for konteksten det skal brukes i. Målgruppen for SAFE er hjemmeboende eldre som står i fare for å utvikle skrøpelighet, med ytterligere fare for funksjonssvikt. SAFE underst $\varnothing t t e r$ systematisk observasjon, vurdering, dokumentasjon og kommunikasjon, og gir klinisk beslutningsst $\varnothing t t e$ for hjemmesykepleieren.

SAFE er et verktøy som har til hensikt å avdekke tidlige tegn på subakutt og akutt funksjonssvikt hos eldre. Det er et erfarings- og forskningsbasert verktøy som brukes til strukturert og systematisk observasjon og vurdering av eldre mottakere av langvarige helse- og omsorgstjenester.

SAFE tar hensyn til kompleksiteten som kjennetegner gradvis utvikling av funksjonssvikt eller forverring av tilstand. Verkt $\varnothing y e t$ gir beslutningsst $\varnothing$ tte til helsepersonell, styrker vurderingskompetansen, fremmer samhandling ved mer presis beskrivelse av pasientens tilstand og har en struktur som ivaretar kontinuitet.

SAFE er utviklet spesielt for målgruppen eldre som er i fare for å utvikle skrøpelighet og påfølgende funksjonssvikt. Vi har grunn til å påstå at SAFE er en del av løsningen på de sammensatte utfordringene de kommunale helse- og omsorgstjenestene står overfor.

\section{«Målet med SAFE er å oppdage og identifisere tidlige tegn på funksjonssvikt hos eldre.»}


Å oppdage utvikling eller forverring av sykdom og helsetilstand hos hjemmeboende eldre er en utfordring, om i det hele tatt mulig uten å aktivt se etter slike tegn. I motsetning til i en institusjon deler ikke hjemmetjenestenes helsepersonell og pasienter samme fysiske miljø (1) hvor sykepleier kan gjøre kontinuerlige observasjoner og vurderinger av pasientene over tid. Hjemmesykepleieren arbeider stort sett alene, skal bes $\varnothing$ ke mange pasienter i løpet av en vakt og har begrenset tid hjemme hos pasienten. Med dagens tildeling av tidsressurser, kanskje kun ti minutter til påkledning eller et kvarter til dusj (2). Erfaringsmessig vet vi at også mer komplekse oppgaver som sårstell og stell av sentralt venekateter ofte har en begrenset tidsramme. SAFE er utviklet med bakgrunn i disse utfordringene.

Målet med SAFE er å oppdage og identifisere tidlige tegn på funksjonssvikt hos eldre gjennom systematisk og strukturert observasjon og vurdering, for å kunne utsette eller forhindre $\varnothing \mathrm{kt}$ hjelpebehov og hjelpeavhengighet. Forkortelsen SAFE står for Subakutt/Akutt Funksjonssvikt hos Eldre.

\section{Avdekker funksjonssvikt}

Tilsynelatende små, gradvise fysiologiske, fysiske eller kognitive endringer kan gi skrøpelighet og fare for alvorlig fysisk og psykisk helsesvikt med $\varnothing \mathrm{kt}$ behov for langvarige helsetjenester. Skrøpelighet kan forstås som at personen «har en biologisk alder som er høyere enn den kronologiske, og en forventet gjenstående levetid som er kortere enn gjennomsnittet for sine jevnaldrende» (3).

Skrøpelighet er et resultat av sammensatte prosesser som til sammen svekker personens reservekapasitet og motstand mot for eksempel infeksjoner, følgene etter en fraktur eller forverring av eksisterende sykdom. Får disse sammensatte prosessene pågå uoppdaget, kan det føre til alvorlig helse- og funksjonstap, her betegnet som funksjonssvikt $(4,5)$. 
Wyller (4) har kategorisert funksjonssvikt etter tiden det tar for tilstanden å oppstå: Akutt funksjonssvikt oppstår i løpet av en dag eller i løpet av en uke. Subakutt funksjonssvikt oppstår i løpet av to til fire uker. Kronisk funksjonssvikt oppstår over tre måneder eller mer. Vårt fokus er primært å sette sykepleiere i stand til å avdekke tidlige tegn på fortrinnsvis subakutt, men også akutt funksjonssvikt, for å bidra til å utsette eller forhindre ytterligere forverring av tilstand.

De første tegnene på utvikling av funksjonssvikt viser seg ofte som små hendelser, som økt ust $\varnothing$ het, sansereduksjoner (syn og hørsel), glemsomhet og eliminasjonsproblematikk (4). Etter hvert som funksjonssvikten tiltar, kan utfallet bli gjentatte akutte sykehusinnleggelser og $\varnothing \mathrm{kt}$ hjelpebehov, og i ytterste konsekvens død (6). Funksjonssvikt er en påkjenning for den eldre og dennes pårørende, og det er kostbart for samfunnet.

\section{«Funksjonssvikt er en påkjenning for den eldre.»}

Myndighetene har over tid hatt et uttalt fokus på pasientsikkerhet og tidlig oppdagelse og håndtering av funksjons- og sykdomsforverring gjennom blant annet nasjonale tiltakspakker. Eksempler på dette er pasientsikkerhetsprogrammet (7), reformer som samhandlingsreformen (8) og Leve hele livet (9), samt nye roller for sykepleiere som avansert klinisk allmennsykepleie (10).

Det er et dokumentert behov for $\varnothing \mathrm{kt}$ kompetanse hos sykepleiere i kommunehelsetjenesten (11), og det er behov for metoder for å identifisere pasienter med risiko for å utvikle skrøpelighet og slik avdekke tidlige tegn på funksjonssvikt for å kunne igangsette tidlig innsats (12). 
Det er bred enighet om at tidlig innsats vil kunne forhindre, redusere eller forebygge utvikling av alvorlig helsesvikt og omfattende hjelpebehov $(12,13)$. En nyere kunnskapsoppsummering slår imidlertid fast at det per i dag ikke finnes retningslinjer eller verkt $\varnothing y$ for å avdekke risiko for $\varnothing \mathrm{kt}$ hjelpebehov blant

hjemmeboende eldre (12).

\section{Hvordan bruke SAFE?}

Når en pasient mottar hjemmesykepleie, foretas systematisk observasjon og vurdering av pasientens behov, ressurser og baseline funksjonsnivå (her betegnet «normaltilstand») ved hjelp av SAFE. Den strukturerte dokumentasjonen av dette ligger til grunn for å oppdage endringer i helsesituasjonen. Sykepleierne som arbeider i hjemmetjenesten, har ansvar for å følge opp et gitt antall pasienter, enten som primærkontakt, tjenesteansvarlig eller som en del av et arbeidslag. Systematisk bruk av SAFE bidrar til at sykepleier blir kjent med pasientens normaltilstand og lettere kan avdekke endringer og slik styrke oppfølgingen av pasienten.

SAFE består av 13 hovedområder for observasjon og vurdering. 
Sykepleier, som helst er pasientens primærkontakt eller tjenesteansvarlige sykepleier, gjør regelmessige observasjoner og vurderinger av pasienten ved å følge strukturen i SAFE. Man leter punktvis etter subakutte endringer under gul kategori og eventuelt akutte endringer i rød kategori. Hvis det ikke er endringer knyttet til de gule eller røde vurderingskategoriene, markeres det for grønn kategori for «ingen endring». En eller flere gule markeringer gir gul status, en eller flere røde markeringer gir rød status. Grønn status gjelder imidlertid kun ved utelukkende grønne markeringer. Til slutt konkluderes det med en SAFEstatus basert på forekomst av gule og/eller røde, eller grønne markeringer. For å avgjøre om det er en endring eller ikke tar man med faglig skjønn utgangspunkt i pasientens normaltilstand, dokumentert i journal eller forrige SAFE-status til sammenlikning og oppfølging.

\section{«Observasjoner og vurderinger ved hjelp av SAFE foretas etter oppsatt intervall.»}

Hvilke oppfølgingstiltak sykepleier kan gjøre basert på SAFE-status, for eksempel når lege bør kontaktes, er foreslått til slutt i SAFE.

Observasjoner og vurderinger ved hjelp av SAFE foretas etter oppsatt intervall. I samhandlingsprosjektet (14) hvor SAFE ble utviklet, var intervallet satt til hver 14. dag, noe som opplevdes for ofte av sykepleierne - særlig når pasientene var stabile. Vårt forslag er at intervallet settes som en hovedregel én gang per måned, men at sykepleier, gjerne i samarbeid med pasientens fastlege, vurderer kortere intervall på bakgrunn av pasientens tilstand. SAFE bør utføres rutinemessig på dagtid.

Det anbefales også at det foretas SAFE-vurdering ved utskrivelse fra sykehus eller institusjon og ved mistanke om endringer. 
De 13 hovedområdene svarte i utgangspunktet til statusområdene i EPJ-systemet Gerica, i den hensikt å basere SAFE på noe som for sykepleierne var kjent (14). Det ble foretatt en revisjon av første versjon i forbindelse med forskningsprosjektet som omtales nedenfor. Den første revisjonen besto kun av tydeliggiøring av språk og begreper. Som vist i tabell 1 er rekkefølgen på både de 13 områdene og fargekodene endret fra første og andre versjon til tredje versjon, basert på erfarings- og forskningsbasert evaluering av SAFE.

Figur 1. De tre versjonene av SAFE, i kronologisk rekkefølge

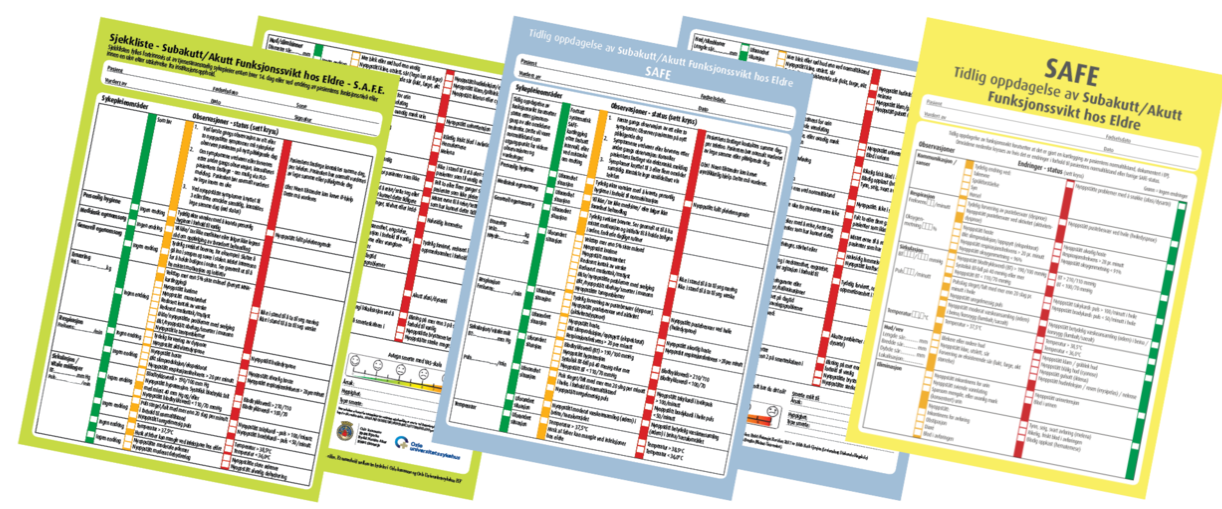

Last ned skjemaet her:

$\underline{\text { SAFE versjon } 3(2018)}$

Evalueringen av SAFE, med påfølgende revisjon, er basert på følgende:

1) Fokusgruppeintervjuer med sykepleiere som tok i bruk SAFE i prosjektet «Akutt og subakutt funksjonssvikt hos eldre» og med sykepleiere som ikke kjente til SAFE.

2) Intervjuer med a) seksjonsledere og b) mellomledere i bydeler som har deltatt og en bydel som ikke deltok i prosjektet.

3) En masteroppgave som inkluderte en litteraturstudie og samsvarsanalyser (15). 
4) Evaluering gjennom utprøving av SAFE i to bydeler som ikke var en del av det nevnte samhandlingsprosjektet, samt fokusgruppeintervjuer med sykepleierne som anvendte SAFE.

Resultater fra de ulike delprosjektene vil bli publisert i internasjonale vitenskapelige tidsskrifter.

\section{Tydeligere tilnærming}

Rekkefølgen på hovedkategoriene ble justert for å samstemme bedre med ABCDE-vurderingen. ABCDE er i tiltakspakken for pasientsikkerhetsprogrammet anbefalt som metode for klinisk observasjon og vurdering (7).

Tabell 1. ABCDE -vurderingen

\begin{tabular}{|lll|}
\hline A & Airways & (luftveier) \\
B & Breathing & (respirasjon) \\
C & Circulation & (sirkulasjon) \\
D & Disability & (nevrologi) \\
E & Exposure & (helkroppsunders $\varnothing$ kelse) \\
\hline
\end{tabular}

Fargerekkefølgen ble endret fra grønn-gul-rød til gulrød-grønn for å tydeliggjøre fokus på de subakutte endringene. Grønn er plassert til slutt for å aktivt kvittere om det er «ingen endring» i stedet for å gjøre dette aller først, før det subakutte eller akutte er vurdert. Beslutningsstøtten i SAFE er plassert til slutt, ikke først som i de forrige versjonene. Dette for å tydeliggiøre at SAFE-kartleggingen og observasjonene må dokumenteres og tiltak må igangsettes og følges opp. NEWS - et etablert verkt øy for vurdering av akutt tilstand (16) - er nå inkludert som et handlingsalternativ når sykepleier oppdager akutte endringer eller mistenker akutte endringer utenom SAFE-intervallet (se vedlagt SAFE, versjon 3). 


\section{Behov for andre verktøy}

Det finnes ulike enkeltstående verkt Øy for å kartlegge funksjonsnivå eller for å avdekke underliggende sykdom og/eller funksjonssvikt - eksemplifisert i tabell 2. Felles for disse er at de benyttes til å observere og vurdere ett eller få områder.

I SAFE tas det hensyn til kompleksiteten som kjennetegner eldre pasienters gradvise funksjonssvikt eller forverring av tilstand gjennom observasjon og vurdering av mange og sammensatte områder. Det er imidlertid ofte nødvendig å tegne et tydeligere bilde av eller bidra til mer spesifikk diagnostisering av pasientens tilstand. Gjennom denne systematiske vurderingen vil bruk av SAFE bidra til å avdekke behov for bruk av andre og komplementære observasjons- og vurderingsverkt $\varnothing y$. Se tabell 3 for oversikt over SAFEområdene i dagens versjon, observasjoner som skal gjøres, nødvendig klinisk utstyr samt eksempler på supplerende observasjons- og vurderingsverkt $\varnothing y$.

I løpet av arbeidet med SAFE har vi gjentatte ganger mottatt spørsmål om forskjellene mellom SAFE og NEWS og om det ene erstatter det andre.

Pasientsikkerhetsprogrammet anbefaler både spesialist- og kommunehelsetjenesten å benytte strukturerte verktøy for tidlig oppdagelse av forverret tilstand. I et pasientforløpsperspektiv anser vi det som nyttig å følge opp pasienten i forbindelse med akutt sykehusinnleggelse og i sårbar hjemkomstfase med både SAFE og NEWS. En akutt endring i pasientens tilstand vil utløse at sykepleier beregner NEWS-skår for å få en videre beslutningsst $\varnothing t t e$. NEWS og SAFE er, slik vi ser det, komplementære verktøy. 
Tabell 2. SAFE-områdene i versjon 3, obervasjoner, nødvendig klinisk utstyr, samt eksempler på supplerende observasjons- og vurderingsverktøy

\begin{tabular}{|c|c|c|c|}
\hline $\begin{array}{l}\text { SAFE- } \\
\text { områder }\end{array}$ & $\begin{array}{l}\text { Subjektive } \\
\text { observasjoner }\end{array}$ & $\begin{array}{l}\text { Objektive } \\
\text { observasjoner }\end{array}$ & $\begin{array}{l}\text { Supplerende verktøy*, } \\
\text { inkludert klinisk utstyr }\end{array}$ \\
\hline $\begin{array}{l}\text { Kommunikasjon/ } \\
\text { sanser }\end{array}$ & $\begin{array}{l}\text { Taleevne } \\
\text { Språkforståelse } \\
\text { Syn } \\
\text { Hørsel }\end{array}$ & & $\begin{array}{l}\text { NEWS (16) } \\
\text { FAST (17) }\end{array}$ \\
\hline Respirasjon & Pustebesvær & $\begin{array}{l}\text { Respirasjonsfrekvens } \\
\text { Oksygenmetning }\end{array}$ & $\begin{array}{l}\text { NEWS } \\
\text { Pulsoksimeter }\end{array}$ \\
\hline Sirkulasjon & $\begin{array}{l}\text { Uregelmessig/regelmessig } \\
\text { puls Væskeansamling } \\
\text { i beina/korsryggen }\end{array}$ & $\begin{array}{l}\text { Blodtrykk } \\
\text { Puls } \\
\text { Temperatur }\end{array}$ & $\begin{array}{l}\text { NEWS } \\
\text { Blodtrykksapparat } \\
\text { Stetoskop } \\
\text { Termometer }\end{array}$ \\
\hline Hud/vev & $\begin{array}{l}\text { Farge } \\
\text { Grad av fuktighet } \\
\text { Sår, utslett } \\
\text { Lukt }\end{array}$ & Størrelse på sår & $\begin{array}{l}\text { TIME (18) } \\
\text { MEASURE (19) }\end{array}$ \\
\hline Eliminasjon & $\begin{array}{l}\text { Inkontinens } \\
\text { Retensjon } \\
\text { Farge og konsistens }\end{array}$ & & Urinstix (20) \\
\hline Ernæring & $\begin{array}{l}\text { Kvalme } \\
\text { Munnt } \varnothing \text { rrhet } \\
\text { Redusert inntak } \\
\text { av næringsmidler } \\
\text { Matlyst } \\
\text { Svelging } \\
\text { Munnhule } \\
\text { Tannstatus }\end{array}$ & $\begin{array}{l}\text { Vekt } \\
\text { Andel vekttap }\end{array}$ & $\begin{array}{l}\text { Personvekt } \\
\text { Målebånd (>2 meter) } \\
\text { BMI (kroppsmasseindeks) } \\
\text { MNA (21) } \\
\text { NUFFE (22) }\end{array}$ \\
\hline Fysisk funksjon & $\begin{array}{l}\text { Ustøhet } \\
\text { Falltendens } \\
\text { Reise/sette seg } \\
\text { Gangfunksjon } \\
\text { Tremor } \\
\text { Stivhet } \\
\text { Bevegelighet i ledd } \\
\text { Symmetri } \\
\text { Kraft }\end{array}$ & & $\begin{array}{l}\text { FAST } \\
\text { ADL-vurdering } \\
\text { IPLOS (23) }\end{array}$ \\
\hline $\begin{array}{l}\text { Generell } \\
\text { egenomsorg }\end{array}$ & Boevne & & $\begin{array}{l}\text { ADL-vurdering } \\
\text { IPLOS }\end{array}$ \\
\hline $\begin{array}{l}\text { Personlig hy- } \\
\text { giene }\end{array}$ & $\begin{array}{l}\text { Evne til kroppsstell } \\
\text { og påkledning }\end{array}$ & & $\begin{array}{l}\text { ADL-vurdering } \\
\text { IPLOS }\end{array}$ \\
\hline $\begin{array}{l}\text { Medisinsk } \\
\text { egenomsorg }\end{array}$ & $\begin{array}{l}\text { Inntak av legemidler } \\
\text { Følge forordninger }\end{array}$ & & $\begin{array}{l}\text { Legemiddelgjennomgang } \\
\text { (24) }\end{array}$ \\
\hline Søvn/hvile & $\begin{array}{l}\text { Grad av våkenhet/trøtthet } \\
\text { Søvnmønster }\end{array}$ & & $\begin{array}{l}\text { 4AT (25) } \\
\text { SAMI (26) }\end{array}$ \\
\hline $\begin{array}{l}\text { Psykisk/kognitiv } \\
\text { funksjon }\end{array}$ & $\begin{array}{l}\text { Stemningsleie } \\
\text { Orienteringsevne } \\
\text { Bevissthetsnivå } \\
\text { Årvåkenhet }\end{array}$ & & $\begin{array}{l}\text { 4AT (25) } \\
\text { MMSE (27) }\end{array}$ \\
\hline Smerte & Smerteuttrykk & Smertekartlegging & Numeric Rating Scale (NRS) \\
\hline
\end{tabular}

*De utvalgte supplerende verktøy er kun eksempler og ikke en uttømmende oversikt. En oversikt over tilgjengelige skalaer og tester finnes på Aldring og helses nettsider (27). Andre anbefalte retningslinjer og verktøy finnes på pasientsikkerhetsprogrammet.no

\section{Strukturert dokumentasjon}


Tilgjengelig informasjon om pasientens tilstand, reaksjoner på denne samt helsepersonells relaterte aktiviteter er nødvendig for å sikre kontinuitet, pasientsikkerhet og kvalitet $(1,17)$. I hjemmesykepleien er det tradisjon for å dokumentere fortløpende og kronologisk. Det vil si at helsepersonellet beskriver hva som har skjedd i løpet av en vakt og hva de har gjort. Dokumentasjonen nedtegnes kronologisk i pasientjournalen uten en form for fast struktur eller rekkefølge utover dato og type vakt (18). Dokumentasjonen fremstår da som ustrukturert, og det er vanskelig å følge hva helsepersonellet har observert, vurdert, besluttet og gjort (18).

Bruk av SAFE danner grunnlag for en mer strukturert dokumentasjon, gitt at dokumentasjonen følger verktøyets struktur i dokumentasjonssystemet. International Classification of Nursing Practice (ICNP) er av Norsk Sykepleierforbund og Direktoratet for e-helse anbefalt som fagterminologi for sykepleiepraksis og -dokumentasjon (19). SAFE er gjennom sin sykepleiefaglige struktur kompatibelt med bruk av ICNP, noe som styrker nytten av SAFE ytterligere.

Bruk av SAFE danner også et godt grunnlag for å strukturere informasjon til samarbeidende helsepersonell, ofte fastlege eller legevakt. I en strukturert ISBAR-samtale (tabell 3) (7) vil informasjon fra SAFE gi en presis begrunnet fremstilling av endringer av pasientens tilstand, $\mathrm{i}$ motsetning til skjønnsmessige beskrivelser av subjektive observasjoner. 


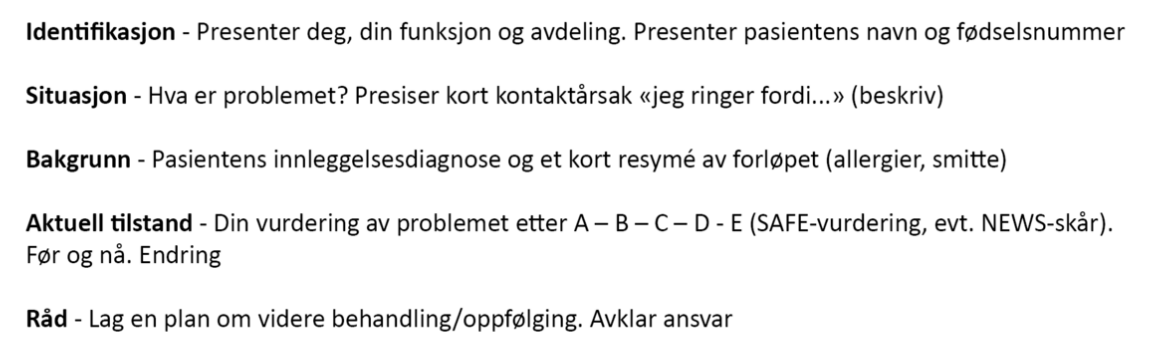

Kilde: Pasientsikkerhetsprogrammet.no

Det er naturlig at hjemmetjenesten benytter SAFE i sin kliniske praksis, som grunnlag for samhandling og kommunikasjon med helsepersonell i primærhelsetjenesten samt pasienter og pårørende. SAFE kan også bidra til mer strukturert samhandling og kommunikasjon mellom spesialisthelsetjenesten og kommunehelsetjenesten, innad og på tvers av helsetjenestenivåene.

\section{Bedre behandling}

SAFE har et betydelig potensial for å muliggjøre at sykepleiere identifiserer tegn på funksjonssvikt hos eldre tidligere enn de gjør i dag. Resultater fra studien som ligger til grunn for revisjon av SAFE, bekrefter dette. A identifisere tidlige tegn på funksjonssvikt vil igjen kunne forhindre eller utsette ytterlige funksjonssvikt. Når relevante intervensjoner blir satt i gang tidlig, vil det sikre at pasienten blir lagt inn på sykehus eller får opphold på sykehjem, eventuelt forhindre eller utsette at det skjer.

\section{«En kan anta at SAFE også kan være nyttig og relevant for bruk i sykehjem.»}

SAFE er utviklet spesielt for målgruppen hjemmeboende eldre som står i fare for å utvikle skrøpelighet, men en kan anta at SAFE også kan være nyttig og relevant for bruk i sykehjem. 


\section{Bør bli digital}

Det er et mål å digitalisere og implementere SAFE i

klinisk praksis, og forarbeider til dette er i gang.

Digitalisering av SAFE, som inkluderer utvikling av algoritmer for standardisering av vurdering og beslutningsst $\varnothing t t e$, og som virker i samspill med sykepleiers faglige skjønn, vil forenkle bruk, styrke verktøyets pålitelighet og de kliniske vurderingenes gyldighet.

\section{«Det er et mål å digitalisere og implementere SAFE i klinisk praksis.»}

Per i dag tas SAFE i papirversjon med ut til pasient. Resultatene dokumenteres i EPJ (Gerica) etter tjenestens daglige journalføringsrutiner. Vitalia dokumenteres i labjournal. Ved systematisk dokumentasjon av vitale data over tid lages en oversiktlig graf i elektronisk kurve. Om det er endringer eller ikke, jf. SAFE-kartleggingen, samt hvilke tiltak som settes i gang, dokumenteres etter lokale rutiner på det enkelte tjenestested.

Vi er i ferd med å utarbeide opplæringspakker og kan bistå i implementering av SAFE i klinisk praksis. Mer informasjon kan fås ved å kontakte førsteforfatter, Senter for fagutvikling og forskning eller Utviklingssenter for sykehjem og hjemmetjenester.

\section{Om prosjektet}

SAFE er revidert og evaluert i hjemmetjenesten i Oslo kommune gjennom et postdoktorprosjekt som er delvis finansiert av Oslo universitetssykehus (støtte til protokollutvikling) og Norsk Sykepleierforbund (forskningsmidler). SAFE ble utviklet i samhandlingsprosjektet «Akutt og subakutt funksjonssvikt hos eldre». Prosjektet ble ledet av Oslo universitetssykehus ved Stab samhandling og internasjonalt samarbeid og gjennomført i samarbeid med Generell indremedisinsk avdeling (OUS) og Geriatrisk akuttavdeling (OUS), Oslo kommune ved hjemmebaserte tjenester og fastleger i Bydel Bjerke, Bydel Nordre Aker og Bydel Østensjø. 


\section{Referanser}

1. Gjevjon ER. Kontinuitet i hjemmesykepleien vanskelige vilkår, men gode muligheter. Tidsskrift for omsorgsforskning. 2015;1(1):18-26.

2. Holm SG. Knapt med tid i hjemmetjenesten - om kjøreruter, skjulte tjenester og tidspress. (Doktorgradsavhandling.) Bodø: Nord Universitet; 2017.

3. Wyller TB. Frail - skrøpelig, sårbar eller skjør? Tidsskr Nor Legeforen. 2014 desember; 134(23):2300.

4. Wyller TB. Geriatri: en medisinsk lærebok. Oslo: Gyldendal Akademisk; 2015.

5. Lang PO, Michel JP, Zekry DJG. Frailty syndrome: a transitional state in a dynamic process. Gerontology. 2009;55(5):539-49.

6. Fried LP, Tangen CM, Walston J, Newman AB, Hirsch C, Gottdiener J, et al. Frailty in older adults: evidence for a phenotype. J Gerontol A Biol Sci Med Sci. 2001 Mar; 56(3):M146-56.

7. Pasientsikkerhetsprogrammet. Tidlig oppdagelse av forverret tilstand. Oslo: I trygge hender 24-7; 2017. Tilgjengelig fra: https://www.pasientsikkerhetsprogrammet.no/omoss/innsatsomr\%C3\%A5der/tidlig-oppdagelse-avforverret-tilstand (nedlastet 25.03.2019).

8. Meld. St. nr. 47 (2008-2009). Samhandlingsreformen - Rett behandling - på rett sted - til rett tid. Oslo: Helse- og omsorgsdepartementet; 2008.

9. Helse- og omsorgsdepartementet. Leve hele livet En kvalitetsreform for eldre. Oslo: Helse- og omsorgsdepartementet; 2018. IS-2674. Tilgjengelig fra: https://www.regjeringen.no/no/tema/helse-ogomsorg/innsikt/leve-hele-livet/id2547684/ (nedlastet 11.11.2018). 
10. Helsedirektoratet. Videreutdanning for sykepleiere - Hvordan sikre at behovet for avansert breddekompetanse blir ivaretatt i fremtiden? Oslo: Helsedirektoratet; 2017.

11. Bing-Jonsson PC, Hofoss D, Kirkevold M, Bjørk IT, Foss C. Sufficient competence in community elderly care? Results from a competence measurement of nursing staff. BMC nursing. 2016;15(1):5.

12. Husebø B, Erdal A, Kjellstadli C, Bøe JB. Oppsummering av kunnskap og forskningsresultater som del av kunnskapsgrunnlaget for Leve hele livet en kvalitetsreform for eldre. Bergen: Sefas; 2017.

13. Næss G, Kirkevold M, Hammer W, Straand J, Wyller TB. Nursing care needs and services utilised by home-dwelling elderly with complex health problems: observational study. BMC Health Serv Res. 2017;17(1):645.

14. Glattre E, Gjevjon ER, Skredsvig K. Sluttrapport for prosjektet Akutt og subakutt funksjonssvikt hos eldre 2012-2013. Oslo: Oslo universitetssykehus; 2014.

15. Johansen S. Systematisk identifisering av den gamle skrøpelige pasient med risiko for reinnleggelse til kommunal akutt døgnenhet-KAD.

(Masteroppgave.) Oslo: Universitetet i Oslo; 2017.

16. Royal College of Physicians. National Early Warning Score (NEWS): Standardising the assessment of acute-illness severity in the NHS. London: Royal College of Physicians; 2012.

17. Helse- og omsorgsdepartementet. Forskrift om pasientjournal. Oslo: Helse- og omsorgsdepartemente; 2001. Tilgjengelig fra: https://lovdata.no/dokument/SF/forskrift/2000-12-21$\underline{1385}$ (nedlastet 11.11.2018). 
18. Gjevjon ER, Helles $\varnothing$ R. The quality of home care nurses' documentation in new electronic patient records. J Clin Nurs. 2010;19(1-2):100-8.

19. Direktoratet for e-helse. Terminologi for sykepleiepraksis. Oslo: Direktoratet for e-helse; 2018. Rapport 1028. 